\title{
Fronteiras fluídas: Rio Grande do Sul e a Banda Oriental no processo de fixação de limites
}

\author{
Fluid borders: Rio Grande do Sul and Eastern Band in the process of setting limits
}

Fronteras de Fluidos: Río Grande del Sury Este de la banda en el proceso de límites de ajuste

Ana Luiza Setti Reckziegel ${ }^{*}$

\section{Resumo}

Este artigo tem como objetivo analisar o processo de fixação dos limites entre a região do Rio Grande do Sul e a Banda Oriental durante o século XVI e início do século XIX. Aborda os distintos tratados de limites celebrados entre as Coroas portuguesa e espanhola para dividir as porções coloniais da América do Sul e a dificuldade no seu cumprimento na porção meridional, visto que ali se configurou uma região cuja história de interação desfazia o que a lógica estatal estabelecia.

Palavras-chave: Fronteira. Limites. Região.

\section{Considerações iniciais}

A territorialidade de um Estado exige uma correspondente demarcação da sua soberania mediante o estabelecimento de fronteiras. Na Idade Média, por exemplo, o termo empregado era a marca ou linha de demarcação de dois sistemas de poder, que se caracterizava pela falta de estabilidade. Comumente, a fronteira constituía-se em uma zona sem definição precisa e, devido à falta de segurança, despovoada. Tal situação perdurou até o século XIII, quando começa a surgir uma tendência ao estabelecimento de limites mais explícitos. A transformação da marca em fronteira se consumou no século XIII, decorrente da evolução da ideia

\footnotetext{
Doutora em História. Professora titular do Programa de Pós-Graduação em História e do curso de graduação em História da UPF. E-mail: analuiza@upf.br

Recebido em 25/03/2015 - Aprovado em 15/04/2015 http://dx.doi.org/10.5335/hdtv.15n.2.5650
} 
de grupo e território comum, por sua criada exigência da defesa militar.

Na evolução do conceito de fronteira, ocupa lugar de destaque a cartografia, sobretudo a partir da Renascença, quando se fez necessário que figurassem nos mapas os limites dos Estados. A partir de então, os compêndios políticos não deixaram de se ocupar desse problema (DICIONÁRIO..., 1986).

Também se buscou na geografia outros elementos que pudessem demarcar a separação entre os Estados e, ao mesmo tempo, contê-los em um todo homogêneo. No entanto, até a constituição dos Estados nacionais de base democrática nem sempre se procurou fazer com que as fronteiras geográficas coincidissem com as da nacionalidade. É evidente que tanto a origem étnica, quanto a religião, a língua, as atividades econômicas, ou a combinação de um ou mais desses elementos, não acabam de forma abrupta em um rio, em uma cadeia de montanhas, lago ou pântano. Menos ainda perdem a função em qualquer linha que possa ser traçada em relação às características físicas.

Em virtude dessa sobreposição e mescla das atividades humanas, torna-se compreensível que a fixação dos limites deva ser acompanhada de certo grau de arbitrariedade; porém, é menos provável que seja aceita quando não estiver delimitada por características físicas que tenham função separadora.

A zona de fronteira rio-grandense-oriental passa a ser não apenas uma extensão dos limites, mas sim uma área de interação, interdependência e complementaridade. A esse propósito torna-se importante distinguirmos os conceitos de fronteira e limites.

\section{Limites e fronteiras no sul da América}

A fronteira é orientada para fora; constitui-se em uma zona de contato e pressupõe avanço, conhecimento, permeabilidade e intercâmbio. O limite, por seu turno, diz respeito diretamente a uma linha de separação definida.

Sobre a diferença entre os dois conceitos, Martin afirma:

[...] hoje o "limite" é reconhecido como linha, e não pode portanto ser habitada, ao contrário da "fronteira" que ocupando uma faixa, constitui uma zona, muitas vezes bastante povoada, onde os habitantes dos estados vizinhos podem desenvolver intenso intercâmbio (MARTIN, 1992, p. 72).

A obra de Backheuser (1942) aponta para um rol de regras ou leis espaciais de fronteiras, que merecem ser mencionadas. A primeira refere-se à lei da força, a qual explicita que a fixação da fronteira é fruto de um ato de vontade dos Estados vizinhos-competidores, atuando de acordo, impondo sua vontade ao outro de forma individual ou auxiliados por terceiros, cujo peso contribui para uma fixação igualitária ou de modo a inclinar a balança a favor de um dos Estados fronteiriços. A segunda, a lei da dinâmica, considera que como resultado das pressões recíprocas, nenhuma fronteira tem caráter estável e definitivo, senão que é a expressão de um equilíbrio transitório. A terceira regra, a lei da fricção, defende a ideia de que a fronteira configura-se como zona de friç̧ão entre os Estados vizinhos. Por último, a lei da pressão aplicada infere que a pressão exercida em cada lado da fronteira está em relação direta com a potência de cada um dos Estados 
vizinhos bem como dos recursos e forças à sua disposição.

O exposto prevê, pois, que na chamada zona de fronteira há estabelecida uma pré-disposição à tensão, ao confronto e à disputa de influência político-estratégica para a região. É importante para a questão que ora analisamos insistirmos na explicitação dos conceitos de limite e fronteira. Observando a obra de Moodie, percebemos que para o autor, mesmo que os limites fiquem quase sempre dentro das fronteiras, há uma diferença significativa inerente às suas diversas naturezas e funções. Segundo Moodie, sendo o limite interestatal uma linha, não pode conter recursos materiais; não pode ser habitado nem ser transitado. $\mathrm{O}$ autor salienta que o limite é destinado a separar, visto que seu objetivo não é o da fronteira geográfica, que serve para facilitar a passagem de um para outro ambiente físico, mas assinalar, de maneira irrefutável, o limite do território no qual o Estado exerce sua força soberana. Ainda de acordo com o autor:

Em outras palavras, o limite define a área dentro da qual se desenvolve a organização interna do Estado e ao longo do qual entram em contato diferentes sistemas de organização estatal. É, portanto, mais uma característica política do que geográfica e sua função divisória depende, grandemente, do grau de diferença ou de semelhança entre as organizações em meio às quais fica (MOODIE, 1965, p. 92).

O processo de ocupação do espaço meridional da colônia brasileira com a área platina teve no Tratado de Tordesilhas (1494) seu primeiro marco delimitador. Essa linha imaginária, por não ter sido respeitada como um limite efetivo, gerou entre os dois territó- rios a configuração de uma "área de interação intensa" (FRANCO, 1993), na qual se formou um estrato social e econômico que mesclava características orientais e sul-rio-grandenses. As paragens sulinas, pela proximidade com a fronteira oriental, apresentariam desde logo uma diferenciação significativa com o restante do Brasil português. Seja pela maneira como foi estruturada sua economia, em oposição ao modelo agroexportador colonial, seja pela maior possibilidade de contato com o território platino do que com o próprio governo geral no Brasil.

No que diz respeito à área oriental, referirmo-nos a ela nos séculos XV e XVI é tarefa complexa, uma vez que o território vizinho não era constituído apenas por uma província, mas por três, que os jesuítas denominavam de Uruguai, Tape e Ibiaçá. De acordo com Souza Docca, a denominação de Província do Tape era conhecida desde a segunda metade do século XVI, antes, portanto, da penetração do território sul-rio-grandense pelos jesuítas, que conservaram aquele nome. Por essa época, há também várias referências à Província de Ibiaçá ou Biaçá (DOCCA, 1939, p. 10).

Um dos primeiros viajantes que mencionou o vocábulo Biaçá para designar uma região foi Alvar Nunes Cabeza de Vaca, em 1544. Nessa mesma década, em 1549, Hans Staden também se refere à região. Em 1577, Jaime Resquim firmou contrato para estabelecer no litoral sul-americano quatro cidades, sendo uma em Viaza. Em 1585, Diego de Palma Carillo e o padre Francisco de Salcedo empreenderam, por ordem do bispo de Tucuman, uma viagem a fim de descobrirem o caminho do Rio da Prata a Viaza, e daí ao Brasil. 
Em 1631, o governador de Buenos Aires, Francisco Cespede, escreveu ao rei de Espanha dando notícias das reduções que mandara fundar nas províncias de Tape, Biaçá e Uruguai. No ano de 1635, o governador Pedro Esteban Dávila, refere-se às províncias Uruguai, Tape e Biaçá, e presta informações sobre os índios de cada uma das três. Pelo depoimento do padre Diogo Alfaro, prestado em 1638, sobre as invasões dos mamelucos, verifica-se que esse sacerdote era o superior das reduções do Paraná, Uruguai, Serra dos Tapes e Biaçá, pertencentes aos governos e bispados do Paraguai e do Rio da Prata (DOCCA, 1939, p. 10).

Das informações colhidas na época, infere-se que, no século XVII, Santa Catarina e parte do Rio Grande do Sul eram consideradas uma única província, e dela não faziam parte nem a do Uruguai e nem a do Tape. Havia no vasto território da bacia do rio Uruguai três províncias que eram mencionadas nominalmente, conforme ficou demonstrado, ou chamadas de modo geral províncias do Uruguai.

Pela real cédula de 16 de novembro de 1617, foi criada a província do Rio da Prata, ficando nela compreendido o atual território da República Oriental do Uruguai, sendo que passaram a integrar a província as cidades de Buenos Aires, Santa Fé, Corrientes e Concecion del Bermejo. Em lugar dos Adelantados, particulares a quem o rei confiava uma expedição marítima, concedendo-lhes de antemão o governo das terras que conquistassem, foi criado, em 1776, o Vice-reinado do Rio da Prata, com sede em Buenos Aires, abrangendo os territórios que constituem atualmente a Argentina, o Uruguai, a
Bolívia e o Rio Grande do Sul. Em 1782, o Vice-reinado foi dividido em oito intendências: Buenos Aires, Córdoba, Salta, Asuncion, La Paz, Potosi, Charcas e Cochabamba, que foram, por sua vez, subdivididas em governos e subdelegações (RODRIGUES; SEITENFUS, 1995, p. 15).

Montevidéu passou a constituir um governo dependente da intendência de Buenos Aires. Em 1785, o governador montevideano, coronel Joaquim del Pino, pleiteou a elevação de seu governo à intendência, recebendo parecer contrário do vice-rei espanhol Manuel Inacio Fernandes, que via no pedido do governador ambições pessoais. Somente em 1814 a Banda Oriental foi elevada à categoria de província, passando a ser regida por um governador intendente e iniciando assim sua vida de administração autônoma. No mesmo ano, seu território foi dividido em sete departamentos militares: Montevideo, Maldonado, Cerro Largo, Porongos, Colonia, Vila de Belem e Paisandú.

\section{Fronteira em movimento}

O primeiro povoado da Banda Oriental foi uma redução de índios fundada por padres franciscanos, em meados do século XVII, com o nome de Santo Domingo Soriano, próxima ao rio Uruguai. O povoamento do futuro Uruguai começa, pois, em sul-oeste, e isso é natural, dado que se trata da área mais próxima a Buenos Aires, já então capital do governo do Rio da Prata (CASAL, 1994).

Em 1618, o território oriental passou a depender do governo de Buenos Aires, sendo que a área circunvizinha a essa cidade, cuja base econômica era a pecuária e o co- 
mércio, opôs séria resistência à fundação de povoados no Uruguai, posto que isso possibilitaria a apropriação do gado por quem ali se estabelecesse. Os fazendeiros portenhos preferiam manter essa banda deserta, como depósito de gado ao qual poderiam recorrer para abastecer-se.

Em 1680, o governador do Brasil, Manoel Lobo, com oitocentos soldados e várias famílias de colonos, fundou a Colônia de Sacramento, entreposto com a finalidade de quebrar o monopólio comercial do porto de Buenos Aires, que viria contribuir para a ocupação do território oriental nos séculos posteriores, ao mesmo tempo que inaugura uma época caracterizada pelas lutas contínuas entre as Coroas rivais e por um desordenamento da exploração da riqueza pecuária.

A importância econômica que adquire essa região em função das vaquerias, determina a disposição das autoridades espanholas em frear o avanço lusitano e concomitantemente introduz uma nova dimensão na função histórica do território oriental, que, segundo Melogno, seria a da Banda-frontera, isto é, a faixa-fronteira (MELOGNO, 1976, p. 8-9).

Com a fundação de Montevidéu obteve-se certa organização no modelo de exploração pecuária por meio da divisão das terras a seus habitantes e também do isolamento da Banda Oriental das bases atlânticas portuguesas.

Em território sul-rio-grandense, na mesma época, grupos de açorianos lançavam as pedras fundamentais de Viamão e de Porto dos Casais, na Lagoa dos Patos. Em 1737, ergueram, no areal costeiro, o forte de Jesus-Maria-José, futura cidade de Rio Gran- de, ponta de lança da ocupação territorial portuguesa.

A primeira metade do século XVIII nessas bandas tem como marca registrada uma sociedade militarizada, destinada a combater em lutas fronteiriças, na ocupação política e na exploração do gado. Contudo, além desses pontos urbanos identificados, o campo permaneceu aberto, sem demarcação específica, funcionando na realidade o uti possidetis. A Coroa portuguesa e os fazendeiros sul-rio-grandenses conjugaram seus interesses na contração das fronteiras: a fome de terra e de gado dos proprietários gaúchos avançou mais rapidamente que a institucionalização dos limites (PEREGALLI, 1982).

No que diz respeito à Banda Oriental, é preciso chamar a atenção de que a partir de 1750, com a criação do governo de Montevidéu e com o desenvolvimento da região entorno, surge um elemento deveras importante: o porto - que no decorrer do tempo será um fator relevante na diferenciação entre os homens da cidade e os fazendeiros. Na questão da apropriação das terras fronteiriças, por exemplo, os proprietários deixaram a tarefa nas mãos de capatazes enquanto permaneciam em Montevidéu, na maior parte das vezes, envolvidos com cargos administrativos, ou esperaram que a Coroa espanhola enviasse forças militares para deter o avanço lusitano. Sobre esse aspecto convém considerar que:

Ao começar o século XIX estavam dadas as três constantes da equação histórica da terra oriental: duas delas, de natureza espacial geográfica, a pradaria e o porto; e uma - a fronteira - filha do tempo e do próprio drama dos homens; mas as três inexoravelmente imbricadas na textura dos fatos. 
Para a pradaria e os homens, a fronteira não significou nunca um limite, senão, ao contrário, um mundo de relação contínua e prolongada, o mundo da verdade geográfica, em contradição com a norma legal. Para a cidade, ao invés, a fronteira era um ante-mural de sua retaguarda econômica, fonte básica do intercâmbio ultramarino. É justamente na concepção de limites juridicionais e patrimoniais, definidos e balizados, que vai configurar-se o senhorio montevideano.

Para isto, a pradaria oriental terá sua resposta, uma resposta instintiva de rebeldia, forjada no sentimento arisco do "pago" (MELOGNO, 1976, p. 8-9).

As formas de ocupação territorial espanhola e portuguesa na América meridional cruzaram-se no século XVIII, no norte da Banda Oriental, entre as estâncias de Yapeyú e San Miguel e sobre a área de São Borja e São Nicolau. Sobre essa última vieram a estabelecer-se portugueses por volta de 1733. O avanço luso não se detinha, ativava-se pelo contrário, conduzido no Rio Grande do Sul por Silva Paes, estruturando nas margens do roteiro atlântico o Forte de São Miguel e, em poucos anos, o de Santa Teresa, próximo à Barra do Chuí, hoje território uruguaio.

Entre o início do século XVIII e aproximadamente a data da expulsão dos jesuítas da América espanhola (1767), começa a verificar-se a presença de estâncias na metade norte do Uruguai e na parte ocidental do Rio Grande do Sul, cujo significado pode ser traduzido como uma forma de organização do espaço com fins econômicos e presença humana permanente.

O espaço começava a encher-se, ou, pelo menos, iniciava-se uma rede de comunicação entre vilas do interior, como Melo
(1795), Minas (1784), Rocha (1793), e as cidades costeiras, Montevidéu e Maldonado, e, por sua vez, entre todos esses pontos e certos santuários rurais e fortes militares, únicos outros centros de atração humana na campanha (CASAL, 1994).

Um dos objetivos da fundação dos povoados no norte do Uruguai, como as vilas de Melo e Rocha, era o de reunir as gentes que vagavam pela campanha do norte e do sul do Rio Negro, em um ponto fixo e permanente que se transformasse em referência para aquela região. Consequentemente, isso fomentaria o surgimento de outras vilas, possibilitando fechar a fronteira e deter Portugal em sua dupla ação de conquista de terras e roubo de gado (BENTANCUR, 1982).

Em termos do relacionamento sul-rio-grandense e oriental, é visível a existência de um espaço compartilhado, o qual não raramente foi responsável pela desconsideração das delimitações jurídicas impostas. A estreita vinculação que desde o início ocorre nesse espaço é notada com propriedade por Franco:

Nenhuma grande cadeia de montanhas, nenhum intransponível curso d'água, nenhum deserto ou pantanal inabitável separam o Brasil do Uruguai. E, ao revés, como tudo concorreu para aproximar cultural, social e economicamente os dois povos, o resultado final foi uma área de interação intensa (1993, p. 140).

\section{Faixa fronteira}

Desde que se encontraram em terras sul-americanas, portugueses e espanhóis viveram em constante disputa por seus domínios. Apesar de não ser clara uma linha de 
fronteira entre os dois territórios, ambos os lados trataram de afastar aquela linha cada qual a seu favor. Até 1750, nenhuma tratativa de delimitação tinha surtido efeito concreto.

Nesse período, começavam a esboçarem-se os contornos da Banda Oriental e do Rio Grande do Sul, com as negociações que iriam formalizar o Tratado de Madrid, em 1750, que fixou os pontos da linha divisória entre Portugal e Espanha. As negociações acordaram que haveria paz permanente entre os súditos das duas Coroas, mesmo que essa paz fosse violada na península ibérica. Cedia-se a Colônia de Sacramento pelos Sete Povos das Missões, cujas populações indígenas seriam transferidas a outro trecho do território sob a soberania espanhola. Adotava-se o princípio do uti possidetis de fato, sustentado ou adotado pela Espanha na solução dos litígios registrados entre seus próprios domínios.

$\mathrm{O}$ acordo fora negociado sob o mais rigoroso sigilo a fim de impedir a interferência de Inglaterra e França, interferência contrária aos interesses das dinastias peninsulares. O Brasil português, agora legitimamente reconhecido pela Espanha, era o Brasil realizado geograficamente pelos bandeirantes paulistas e pelos sertanistas do norte, pelos religiosos a serviço do Estado, pelos contingentes militares que haviam ocupado as áreas interiores distantes do litoral do primeiro século do domínio.

Ficava assentado que a fronteira começava em Castilhos Grande, no atual Uruguai, procurava as vertentes da Lagoa Mirim e do Rio Negro para alcançar o Ibicuí, pelo qual descia até o rio Uruguai, seguindo-o até o Peperiguaçu; daí prosseguia até o Iguaçu para alcançar o Paraná, buscando seguir o Iguareí, indo à fonte principal do contravertente mais próximo que desaguasse no Paraguai, por onde continuaria até o Jauru. Uma linha reta avançaria até o Guaporé. Na fronteira seguia as águas desse rio, do Mamoré e do Madeira, até a meia distância da boca do tal afluente do Amazonas, de lá saindo outra linha a buscar as nascentes do Javari, subindo esse até o Solimões para continuar até a boca do Jupurá, por cujo divisor de águas com o Negro passaria ao encontro da cordilheira, que se imaginava separasse a bacia do Orinoco da bacia do Amazonas.

As sitiações em poder dos luso-brasileiros no Rio Negro ficariam devidamente resguardadas. As demarcações foram organizadas sobre as chamadas partidas de limites, sendo três para o sul e três para o norte (REIS, 1985).

Liderando a comissão encarregada do sul, Portugal nomeou o capitão-general do Rio de Janeiro, Gomes Freire de Andrada, a quem se atribuía muito do esforço por realizar-se a política da ordenação dos limites. A Espanha, por seu turno, escolheu o marquês de Val de Lirios. Para o norte, foram escolhidos Francisco Xavier de Mendonça Furtado, capitão-general do Estado do Grão-Pará e Maranhão, por Portugal; e pela Espanha, D. José de Iturriaga (SÃO LEOPOLDO, 1982, p. 76).

No entanto, as demarcações na região norte sequer foram iniciadas; as do sul foram realizadas em grande parte. A segunda e a terceira partida efetuaram amplo reconhecimento dos rios indicados no tratado, apesar das dúvidas que ocorriam em relação a alguns deles, cujo curso ou cuja existência não correspondia ao que figurava no Mapa 
das Cortes, em que fora traçada a fronteira. Além dessa dificuldade, o grande obstáculo aos demarcadores constituiu-se na revolta dos índios missioneiros, episódio que entrou para a história como guerra guaranítica (GOLIN, 1999). Nessas circunstâncias, Gomes Freire recusou-se a receber os Sete Povos antes que os espanhóis os declarassem definitivamente pacificados, ficando a execução do tratado suspensa. Em 1761, firmou-se o Tratado de El Pardo, anulando o de Madrid.

A guerra da Inglaterra contra os Bourbons, na qual Portugal e Espanha colocaram-se em campos opostos, repercutiu na América meridional. Em 1761, Carlos III, rei de Espanha, assinou com a França o chamado Pacto de Família, segundo o qual a Espanha entrava na guerra dos Sete Anos, ao lado da França, Áustria e Rússia, contra a Inglaterra e a Prússia.

Portugal, apesar de solicitado pela Espanha para fazer parte do pacto, manteve-se fiel à aliança com a Inglaterra, motivo pelo qual teve seu território na colônia brasileira invadido, enquanto no Rio da Prata pela quarta vez era atacada a Colônia de Sacramento. A tarefa coube ao então governador de Buenos Aires, D. Pedro de Ceballos, que, com enorme superioridade militar, conseguiu obter a rendição da praça, defendida pelo governador Vicente da Silva da Fonseca, em 1762.

No ano seguinte, desconhecendo o acordo de paz que se realizava na Europa entre as potências beligerantes, Ceballos invadiu Rio Grande. A posse do Rio Grande de São Pedro era o ponto capital das divergências entre Portugal e Espanha, em paz na
Europa, mas não na América, ao contrário do que tentou estabelecer o Tratado de Madrid, de 1750. A tomada do forte de Santa Tecla, pelo sargento-mor Rafael Pinto Bandeira, antecedeu a recuperação do Rio Grande, conseguida em abril de 1776, pelo tenente-general João Henrique Böhm, alemão a serviço de Portugal.

Após tentativas de conversação diplomática, a Espanha revidou com a guerra, montando uma expedição com 13 mil homens, comandados pelo governador Ceballos. A debilidade da reação portuguesa teve como consequência a tomada de Santa Catarina pelos espanhóis e também da Colônia de Sacramento, então pela quinta vez atacada, em 1777. Outros pontos que em consequência do Tratado de Madrid tinham sido ocupados pelos luso-brasileiros também foram objeto de tentativas de reconquista pelos espanhóis.

Nesse contexto de disputas, a mediação da Inglaterra e da França foi decisiva para o encaminhamento de um novo tratado de limites para os domínios ultramarinos das duas Coroas. O Tratado de Santo Ildefonso, firmado a $1^{\circ}$ de outubro de 1777 , era francamente favorável à Espanha, deixando-a com o domínio absoluto e exclusivo do Rio da Prata, estendendo sua bandeira à Colônia de Sacramento e tendo reconhecida sua autoridade sobre os campos do Ibicuí, na margem oriental do Uruguai. Em contrapartida, apenas teve de devolver Santa Catarina, de que havia se apoderado por conquista, e sequer restituir os Sete Povos.

A paz vigente entre Portugal e Espanha, desde 1777, havia sido consolidada ainda mais pela união dos príncipes D. João e 
D. Carlota Joaquina. Com o acesso ao trono espanhol do rei Carlos IV, pai dessa princesa, e com a ascensão de seu marido à regência portuguesa, mais seguras tornavam-se as perspectivas de perfeito entendimento entre as duas monarquias ibéricas.

Entretanto, os acontecimentos de 1789, na França, e a posterior política expansionista de Napoleão Bonaparte alteraram a situação de cordialidade levando a um rompimento de relações, embora breve, entre Portugal e Espanha. Napoleão, no intuito de castigar Portugal pela participação de seus navios nos cruzeiros ingleses no Mediterrâneo, pressionou a Espanha para que quebrasse a aliança com os portugueses, o que foi obtido em 1801.

A retomada da relação espanhol-portuguesa por meio de negociações realizadas em Badajoz, no mesmo ano, tardou a ser divulgada na América. Nesse contexto, apenas conhecida a ruptura das relações, não tardou que rompessem hostilidades entre as populações fronteiriças quando os luso-brasileiros, no Rio Grande de São Pedro, invadiram a Banda Oriental e os Sete Povos das Missões Orientais do Uruguai.

O tenente-coronel Sebastião Xavier da Veiga Cabral da Camara, governador da capitania, providenciou que o exército entrasse imediatamente em campanha, dividindo-o em dois corpos sob o comando do coronel Manoel Marques de Souza e do tenente-coronel Patricio José Corrêa da Camara. O primeiro marchou para a fronteira do Rio Grande e o segundo foi estacionar em Rio Pardo.

Os espanhóis tinham em toda a fronteira pontos fortificados ou guarnecidos, a que chamavam de Guardas. Existiam a Guarda da Lagoa e do Cerrito, próxima a Jaguarão; a Guarda do Quilombo, provavelmente junto ao Arroio Quilombo, no terceiro distriro de Jaguarão; a Guarda de São José, de Santa Rosa, a Fortaleza de Santa Tecla; a Guarda de Taquarembó; a Guarda de Batovy e a Guarda de São Sebastião. O governador da capitania, Veiga Cabral, mandou que o coronel Marques de Souza atacasse o inimigo, e os espanhóis, percebendo o avanço das forças portuguesas, abandonaram as suas guardas e concentraram-se no lugar hoje denominado Cerro Largo, no Uruguai, distante 15 léguas de Jaguarão.

Na região próxima às missões orientais, também havia uma guarnição espanhola, a Guarda de São Martinho, que foi tomada pelos portugueses depois de pequena escaramuça. Quando veio a notícia da paz na Europa essa era a situação, então, por conseguinte, cessaram as hostilidades. Como o novo tratado não fazia menção à revalidação do tratado de 1777, não estabelecendo a causa statu quo ante bellum, como era praxe na época, os portugueses recusaram-se a entregar aos espanhóis suas conquistas, inclusive as Missões, e estenderam a fronteira sul-brasileira ao arroio Chuí e aos rios Jaguarão e Quaraí, passando a dominar exclusivamente a Lagoa Mirim (SILVA, 1922, p. 366).

A partir de 1801, estabelecidos os limites propriamente ditos entre o Uruguai e o Rio Grande do Sul, configura-se a situação de fronteira, chave para o entendimento das relações que se evidenciam bilateralmente.

Com a falta de uma percepção efetiva acerca dos limites entre a área sul-rio-grandense e oriental, contrapôs-se a assinatura 
do Tratado de Badajoz, em 1801, que impôs um novo padrão de relacionamento no qual o aspecto formal e jurídico, ao menos, foi alterado.

Posteriormente a essa nova situação, outras modificações fizeram-se sentir nessa porção da América, especificamente, o encaminhamento do processo de independência das colônias espanholas no Prata e a posterior invasão do território oriental pelas forças militares de D. João VI, tema que foge do proposto neste artigo.

\section{Considerações finais}

A Banda Oriental constituía-se em um território pouco povoado e escassamente urbanizado, cujo principal recurso era o fértil solo de seus campos que concentrava a mais rica reserva de gado do Rio da Prata. Por volta de 1810, havia em torno de $40 \mathrm{mil}$ habitantes, muitos dos quais se dedicavam à caça ao gado alçado. A expansão da pecuária deu origem a uma nova e poderosa classe de fazendeiros, cujas concessões de terras dividiram o país em grandes estâncias, baseadas no trabalho dos gauchos e dos escravos. O desenvolvimento rural refletiu-se também no comércio, principalmente no ramo exportador de charque e couros, bem como no setor naval e de tráfico de escravos.

O sentido da Banda Oriental no contexto do sistema colonial espanhol, além de econômico, era estratégico, devido à sua posição dominante na entrada do Rio da Prata, de onde podia controlar o tráfico de escravos de dentro e de fora desse grande complexo fluvial. Afora isso, a área oriental configurava-se em um amortizador entre o
Brasil e o Rio da Prata, daí ter sido disputada pelas Coroas portuguesa e espanhola.

Em realidade, desde a ocupação das terras do Prata, a zona oriental funcionou como uma espécie de grande estância arrendada por Buenos Aires. A Espanha somente começou a preocupar-se com essa zona após a fundação da Colônia de Sacramento, em 1680, na costa norte do Rio da Prata, que passou a significar concorrência comercial para os interesses espanhóis estabelecidos do outro lado do rio. Em contrapartida fundou Montevidéu, por volta de 1720, a qual cumpriria a função defensiva para, posteriormente, converter-se em capital.

O fato é que a fronteira norte da Banda Oriental permaneceria desguarnecida, e esse vazio estimularia o avanço português sobre aquela região, principalmente na forma de comércio de gado. Compreende-se, pois, que nessas circunstâncias se configurasse o que denominamos de uma região de interação entre o território oriental e o sul-rio-grandense. No decorrer do processo de ocupação desses territórios houve uma séria imbricação de interesses econômicos, familiares e culturais, o que tornava problemática, muitas vezes, a separação da condição oriental da sul-rio-grandense, e vice-versa. Para essa zona, a noção de limite foi um tanto fluída, mesclando-se interesses de indivíduos ou grupos de nacionalidade diversa, que muitas vezes uniram-se em torno de causas estranhas à sua origem estatal propriamente dita. 


\section{Abstract}

The article aims to analyze the process of fixing the boundaries between the Rio Grande do Sul region and the Eastern Band during the sixteenth and early nineteenth century. It discusses the various treaties of limits concluded between the Portuguese Crown and Spanish to divide the colonial portions of South America and the difficulty in complying with the southern portion since there took shape a region whose interaction history undid what the state logic established.

Keywords: Border. Limits. Region.

\section{Resumen}

El artículo tiene como objetivo analizar el proceso de fijación de los límites entre el do Sul, Río Grande y la Banda Oriental durante el siglo XIX y principios del XVI. Se analizan los diversos tratados de límites celebrados entre la Corona portuguesa y española para dividir las porciones coloniales de América del Sur y la dificultad en el cumplimiento de la parte sur ya que no se concretó una región cuya historia interacción deshizo lo que la lógica estatal establecida.

Palabras claves: Frontera. Límites. Región.

\section{Referências}

BACKHEUSER, Everardo. Geopolítica e geografia política. Revista Brasileira de Geografia, Rio de Janeiro: Serviço Gráfico do Instituto Brasileiro de Geografia e Estatística, Separata do n. 1, ano IV, 1942.

BENTANCUR, Arturo Ariel. Contrabando y contrabandistas: histórias coloniales. Montevideo: Arca, 1982.

CASAL, Juan Manuel. La frontera colonial: ocupación territorial de la Banda Oriental del Rio de la Plata (siglos 16, 17 y 18). In: CASTELLO, Iara R.; SCHAFFER, Neiva Otero; LEHNEN, Carlos (Org.). Fronteiras no Mercosul. Porto Alegre: Ufrgs; Prefeitura Municipal de Uruguaiana, 1994. p. 63-68.

SILVA, J. Resende. A fronteira do Brasil. Rio de Janeiro: Imprensa Nacional, 1922.

DICIONÁRIO de Ciências Sociais. Rio de Janeiro: FVG, 1986.

DOCCA, Souza. Limites entre o Brasil e o Uruguai. Rio de Janeiro: Oficina Gráfica, 1939.

FRANCO, Sérgio da Costa. Panorama sociocultural da fronteira Brasil-Uruguai. Revista do Instituto Histórico e Geográfico do Rio Grande do Sul, Porto Alegre, n. 129, p. 29-42, 1993.

GOLIN, Tau. A Guerra Guaranitica. Como os exércitos de Portugal e Espanha destruíram os Sete Povos dos jesuítas e índios guaranis no Rio Grande do Sul. 2. ed. Passo Fundo: UPF Editora, 1999.

MARTIN, André Roberto. Como se constituiu no Brasil a rede de fronteiras internas. Revista do FFLCH - USP, São Paulo, v. 5, p. 73-83, 1992.

MELOGNO, Tabare. Artigas - la causa de los pueblos. Montevideo: EBO, 1976.

MOODIE, A. E. Geografia e política. Rio de Janeiro: Zahar, 1965.

PEREGALLI, Enrique. Como o Brasil ficou assim? São Paulo: Global, 1982. 
REIS, Arthur Cezar Ferreira. Os tratados de limites. In: HOLANDA, Sergio Buarque de. História geral da civilização brasileira. São Paulo: Difel, 1985. v. 1.

RODRIGUES, José Honório; SEINTENFUS, Ricardo. Uma história diplomática do Brasil (15311945). Rio de Janeiro: Civilização Brasileira, 1995.

SÃO LEOPOLDO, José Feliciano Fernandes Pinheiro. Visconde de. Anais da Província de São Pedro. 5. ed. Porto Alegre: Mercado Aberto, 1985. 